\title{
Correction to: Mobility as a service (MaaS): the importance of transportation psychology
}

\author{
Geoff Tomaino $^{1}$ (D) - Jasper Teow ${ }^{2} \cdot$ Ziv Carmon $^{1} \cdot$ Leonard Lee $^{3}$. \\ Moshe Ben-Akiva ${ }^{4} \cdot$ Charlene Chen $^{5} \cdot$ Wai Yan Leong ${ }^{6} \cdot$ Shanjun Li $^{7} \cdot$ Nan Yang $^{2}$. \\ Jinhua Zhao ${ }^{8}$
}

Published online: 19 January 2022

๑) Springer Science+Business Media, LLC, part of Springer Nature 2022

\section{Correction to: Marketing Letters (2020) 31:419-428 https://doi.org/10.1007/s11002-020-09533-9}

The original version of this article contained an error-the acknowledgement below was missing: This research was supported by Singapore's National Research Foundation, under its Behavioural Studies in the Energy, Water, Waste \& Transportation Sectors programme (BSEWWT2017_01).

Publisher's note Springer Nature remains neutral with regard to jurisdictional claims in published maps and institutional affiliations.

The original article can be found online at https://doi.org/10.1007/s11002-020-09533-9.

Geoff Tomaino

geoffrey.tomaino@insead.edu

1 INSEAD, Singapore, Singapore

2 NUS Business School, National University of Singapore, Singapore, Singapore

3 NUS Business School and Lloyd's Register Foundation Institute for the Public Understanding of Risk, Singapore, Singapore

4 MIT's Intelligent Transportation Systems Lab, Cambridge, MA, USA

5 Nanyang Technological University, Singapore, Singapore

6 Land Transport Authority, Singapore, Singapore

7 Cornell University's Environmental \& Energy Economics Lab, Ithaca, NY, USA

8 MIT's Urban Mobility Lab, Cambridge, MA, USA 